\title{
Compact Shaft-Rotating Swerve Drive with Prong Structure for Highly-Maneuverable and Agile Robots
}

\author{
By Miles Vranas ${ }^{*}$ \& Nikos J. Mourtos ${ }^{ \pm}$
}

\begin{abstract}
Robots are becoming increasingly important in our lives. Although many robots are stationary, for example robotic arms, moving robots are of particular interest for many applications. Applications of moving robots today include combating COVID-19 in hospitals, transporting goods in and across warehouses and distribution centers, and moving equipment and instrumentation in space, to name a few. Mobile robots are often required to maneuver rapidly in tight spaces. The best way to achieve this is through a modular assembly called Swerve Drive, which is a driven wheel that can pivot 360 degrees. Three or more modules can be placed at the corners of the robot, allowing high levels of maneuverability, such as, for example, spinning while following a path in any direction. This paper presents the design of a swerve drive module, which improves the current state-of-the-art. The proposed Swerve Drive module has similar properties to current designs available in the market in four out of six metrics defined in this work, while it does significantly better in the other two metrics.
\end{abstract}

Keywords: robotics, mechanical engineering, drivetrain, maneuverability, mobile, swerve-drive

\section{Introduction: The Need for Swerve Drive}

In today's society, moving robots are becoming increasingly important in many applications (Carothers 2014). As machine learning and artificial intelligence become more advanced, mobile robots are able to take on increasingly important tasks. With this advancing technology, a more advanced robot drivetrain is needed to allow robots to operate quicker, more efficiently, and in much smaller spaces. Most drivetrains today operate like tanks or cars. However, Swerve Drive (Swerve Drive Specialties 2021), is dramatically different. It is able to maneuver in ways that no other drivetrain can.

Swerve Drive is a modular assembly, which consists of a driven wheel (blue) and a base, which rotates around the vertical axis running through the center of the wheel. There are two motors, one which drives the blue wheel, and the other which pivots the direction in which the wheel is facing. In Figure 5, the base which rotates around the vertical axis can be seen as well. A robot which utilizes Swerve Drive would typically contain four Swerve Drive modules. A depiction of such a drivetrain is shown in Figure 1, for illustration purposes. Other configurations are possible, such as a drivetrain which utilizes three Swerve Drive modules, or more. This

\footnotetext{
*Mechanical Engineer, Monte Vista Robotics Team, USA.

${ }^{ \pm}$Professor and Chair, Aerospace Engineering, San Jose State University, USA.
} 
allows a robot which utilizes Swerve Drive to spin while moving along any designated path. Each wheel can rotate while at the same time pivoting along the vertical axis. This arrangement allows for increased maneuverability.

Figure 1. Bottom (left) and Top (right) Views of a Drivetrain Utilizing Four Swerve Drive Modules
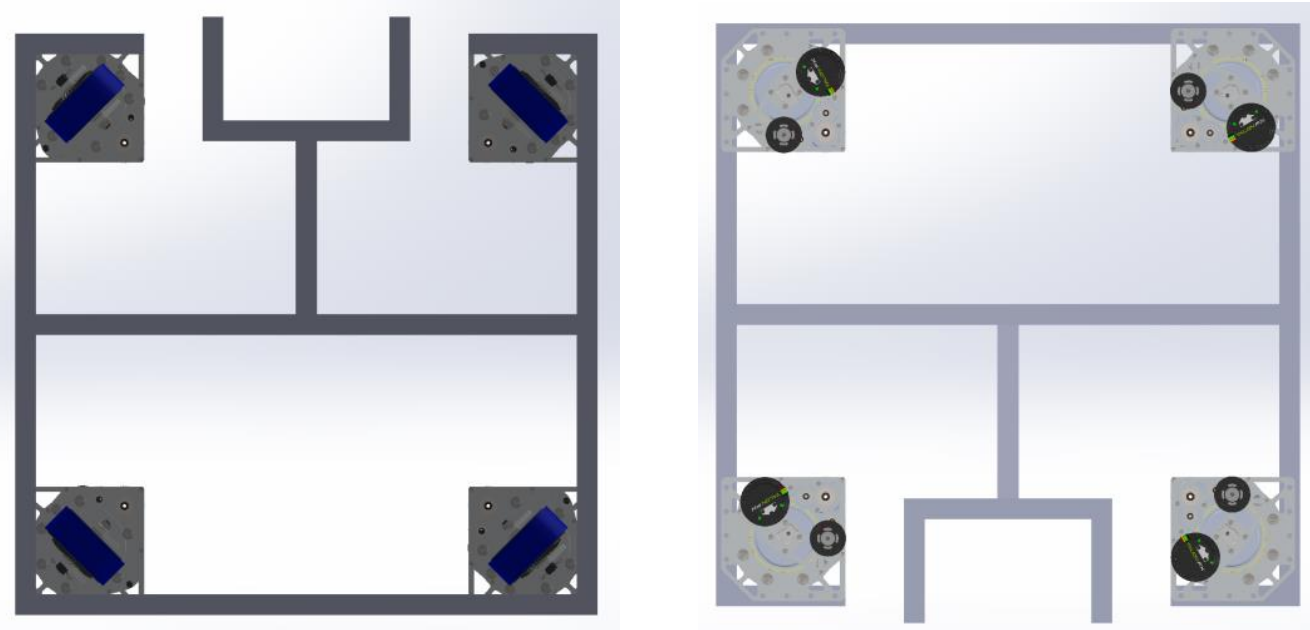

Figure 2 shows paths of a robot using Swerve Drive. As can be seen, the Swerve Drive allows for a better-than-human maneuverability in the given environment.

Figure 2. A Schematic of the Paths and Orientations of a Swerve Drive Robot (green indicates the path, red indicates direction in which the robot is facing, white indicates the position of the robot)

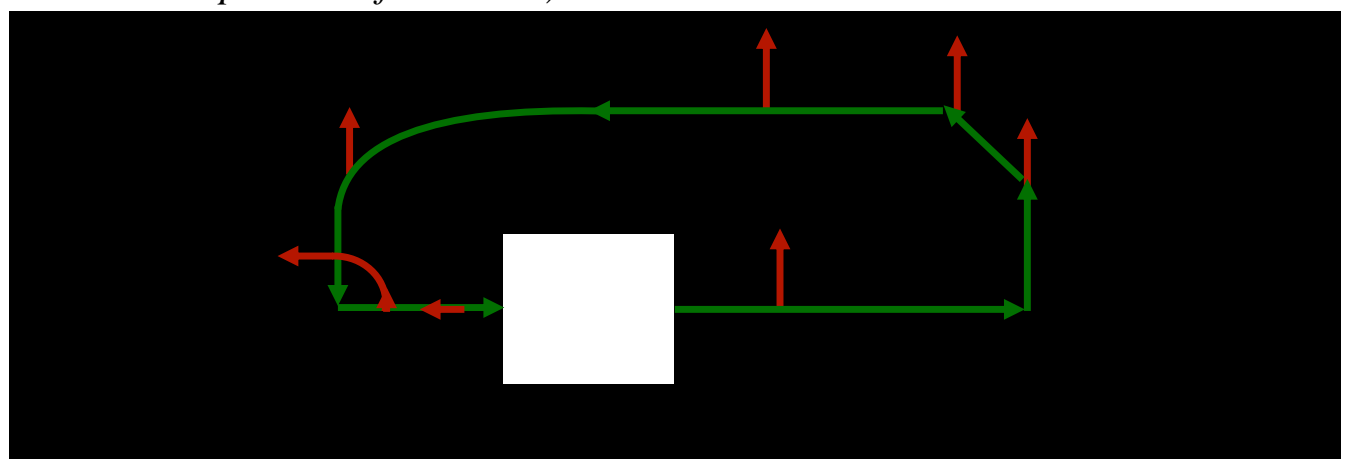

Mobile robots are used to combat COVID-19 (Seidita et al. 2021, Ackerman 2020, Cardona et al. 2020), help healthcare workers in hospitals (Melanson 2018, Bloss 2011), transport goods in and across warehouses and distribution centers (Dunakin 2020, Simon, 2019), in space programs (NASA Technology Transfer Program, Mars 2020 Mission Perseverance Rover), as well as for specific functions in stores (Ciment 2020), to name a few applications. Swerve Drive designs are already in use today (Swerve Central 2021), however, their operation and capabilities allow much room for improvement. This paper presents the design of a Swerve Drive module with improved characteristics. 


\section{Background Review}

Many Swerve Drive robots rely on chains or belts (Swerve Drive Specialties, 2021), which can lose tension with time, causing loss in precision or total failure. Some designs, such as those by Westcoast Products (Westcoast Products, 2021), do not require belts. However, they do require specialized machines, such as highend CNC mills (Tormach 2021, Stepcraft, 2021) and hobbing machines (Lieherr 2021) to produce intricate gears. This increase difficulties and cost in the manufacturing process. Furthermore, existing Swerve Drive modules do not have the encoder placed directly on the rotating wheel mount because of restrictions caused by the placement of components (see for example Westcoast Products 2021), causing poor directional precision. In the proposed design all these issues are resolved, while maintaining low-price, small size, low weight, and structural integrity. In Table 1, the characteristics of the best current state-of-the-art Swerve Drive (Westcoast Products 2021) is listed for comparison.

\section{Methodology}

\section{Design Criteria and Constraints}

Design criteria and constraints were explored in Solidworks (Dassault Systems 2021) and are described below, along with a scoring system that is used in Table 1 to compare the proposed design with the current state-of-the art.

Price for each Swerve Drive module was explored using existing parts from sources such as McMaster Carr (2021) and stock material, such as 60610.25 " aluminum sheets. The target price of each module is set at $\$ 650.00$, below the price of the current state-of-the-art, which is $\$ 685.37$, including all necessary options (Westcoast Products 2021).

Scoring for price:

+10 points if $\$ 650$ or lower

-1 point for every $\$ 50$ over $\$ 650$

Manufacturability expresses the ease of manufacturing and is determined by the number of parts in a single module, as well as the need for specialized manufacturing machines.

Scoring for manufacturability:

+5 points if number of parts is 200 or less; -0.5 point for every 20 parts over 200

+5 points if special equipment worth more than $\$ 5000$ is not necessary to manufacture any part of the module; +0 points otherwise

Overall size is determined by the size of the wheel and motors. The target size for each module is set at a length of 6", a width of 6", and an overall height (from 
the bottom of the wheel to the top of the motor) of 10". This size is less than that of the current state-of-the-art (Westcoast Products 2021).

Scoring for size:

+1 for each 4 " less than 44 " of the perimeter (max 5 points)

+0 if perimeter is greater than 44 "

+1 if height is 1 " less than 15 " (max 5 points)

+0 if height is greater than 15 "

Weight is determined by the weight of the two motors and the wheel, which is approximately 2.5 pounds. The target weight for each module is set to approximately three times that amount or 7.5 pounds.

Scoring for weight:

+1 point for each pound less than 15

+0 points if module weighs 15 pounds or more

Structural Integrity refers to the ability of the module to operate under load. The target criteria are as follows: (a) module can be lifted off the ground without separating, (b) module can operate without falling apart, (c) moving parts operate properly under load, and (d) four modules can support a robot weight of at least 160 pounds.

Scoring for structural integrity:

+2.5 module can be lifted off of the ground without separating

+2.5 module can operate without falling apart

+2.5 moving parts operate properly under load

+2.54 modules can support a robot weight of at least 160 pounds

Precision refers to the ability of the wheel to change direction accurately, as well as to the precision of the directional sensors. The first target is for the encoder to be directly mounted to the rotating wheel mount, so it will directly read the direction the wheel is facing. The second target is to avoid using belts or chains, as they become slacked, causing loss of precision.

Scoring for precision:

+5 encoder is directly mounted on the rotating wheel mount

+5 no belts or chains used

Iterations and Evaluations of Designs Using CAD Tools

Table 1 shows that the Swerve Drive module proposed here provides improved performance over the current state-of-the-art (Westcoast Products 2021), having similar properties in four out of six metrics, while doing significantly better in the other two. 
Table 1. The Given Scores are between 0 (Poor) and 10 (Perfect). A Score of 8 or Above (Marked as Green), Indicates a Sufficient Design

\begin{tabular}{|c|c|c|c|c|c|c|c|}
\hline Iteration & Price & Manufacturability & $\begin{array}{c}\text { Size } \\
(\mathrm{L} \times \mathrm{W} \times \mathrm{H})\end{array}$ & Weight & $\begin{array}{l}\text { Structural } \\
\text { Integrity }\end{array}$ & Precision & $\begin{array}{l}\text { Figure } \\
\text { Number }\end{array}$ \\
\hline 1 & $\begin{array}{c}6.48 / 10 \\
(\$ 826.55)\end{array}$ & $\begin{array}{c}8.45 / 10 \\
\text { (Number of parts is } 262, \text { no } \\
\text { machines over } \$ 5000 \text { are } \\
\text { needed to manufacture any } \\
\text { part of the module) }\end{array}$ & $\begin{array}{c}3.53 / 10 \\
\left(7.94 " \times 9 " x 14^{\prime \prime}\right)\end{array}$ & $\begin{array}{c}\text { 4.73/10 } \\
\text { (10.27 } \\
\text { pounds) }\end{array}$ & $\begin{array}{l}10 / 10 \\
\text { (Module is able } \\
\text { to be lifted off of } \\
\text { the ground } \\
\text { without } \\
\text { separating, can } \\
\text { operate without } \\
\text { falling apart, } \\
\text { moving parts } \\
\text { operate properly } \\
\text { under load, and } 4 \\
\text { modules can } \\
\text { support a robot } \\
\text { weight of at least } \\
160 \text { pounds) }\end{array}$ & $\begin{array}{c}\text { D/10 } \\
\text { (Encoder is } \\
\text { not directly } \\
\text { mounted to } \\
\text { rotating wheel } \\
\text { mount, chains } \\
\text { used) }\end{array}$ & 2 \\
\hline 2 & $\begin{array}{c}6.00 / 10 \\
(\$ 850.94)\end{array}$ & $\begin{array}{l}9.4 / 10 \\
\text { (Number of parts is } 223, \text { no } \\
\text { machines over } \$ 5000 \text { are } \\
\text { needed to manufacture any } \\
\text { part of the module) }\end{array}$ & $\begin{array}{c}3.5 / 10 \\
(8.5 " \times 8.5 " \times 14 ")\end{array}$ & $\begin{array}{c}\text { 4.26/10 } \\
\text { (10.74 } \\
\text { pounds) }\end{array}$ & $\begin{array}{l}5 / 10 \\
\text { (Module is able } \\
\text { to be lifted off of } \\
\text { the ground } \\
\text { without } \\
\text { separating, can } \\
\text { operate without } \\
\text { falling apart, } \\
\text { moving parts do } \\
\text { not operate } \\
\text { properly under } \\
\text { load, and } 4 \\
\text { modules cannot } \\
\text { support a robot } \\
\text { weight of at least } \\
160 \text { pounds) }\end{array}$ & $\begin{array}{c}10 / 10 \\
\text { (Encoder } \\
\text { directly } \\
\text { mounted to } \\
\text { rotating wheel } \\
\text { mount, no } \\
\text { belts or chains } \\
\text { used) }\end{array}$ & 3 \\
\hline 3 & $\begin{array}{c}8.90 / 10 \\
(\$ 705.61)\end{array}$ & $\begin{array}{l}10 / 10 \\
\text { (Number of parts is } 186, \text { no } \\
\text { machines over } \$ 5000 \text { are } \\
\text { needed to manufacture any } \\
\text { part of the module) }\end{array}$ & $\begin{array}{c}7.72 / 10 \\
(5.93 " \times 5.93 " \times 12.28 ")\end{array}$ & $\begin{array}{c}9.25 / 10 \\
(5.75 \\
\text { pounds) }\end{array}$ & $\begin{array}{l}10 / 10 \\
\text { (Module is able } \\
\text { to be lifted off of } \\
\text { the ground } \\
\text { without } \\
\text { separating, can } \\
\text { operate without } \\
\text { falling apart, } \\
\text { moving parts } \\
\text { operate properly } \\
\text { under load, and } 4 \\
\text { modules can } \\
\text { support a robot } \\
\text { weight of at least } \\
160 \text { pounds) }\end{array}$ & $\begin{array}{c}10 / 10 \\
\text { (Encoder } \\
\text { directly } \\
\text { mounted to } \\
\text { rotating wheel } \\
\text { mount, no } \\
\text { belts or chains } \\
\text { used) }\end{array}$ & 4 \\
\hline
\end{tabular}




\begin{tabular}{|c|c|c|c|c|c|c|c|}
\hline Iteration & Price & Manufacturability & $\begin{array}{c}\text { Size } \\
(\mathrm{L} \times \mathrm{W} \times \mathrm{H})\end{array}$ & Weight & $\begin{array}{l}\text { Structural } \\
\text { Integrity }\end{array}$ & Precision & $\begin{array}{l}\text { Figure } \\
\text { Number }\end{array}$ \\
\hline Final (4th) & $\begin{array}{c}10 / 10 \\
(\$ 649.07)\end{array}$ & $\begin{array}{l}10 / 10 \\
\text { (Number of parts is } 189 \text {, no } \\
\text { machines over } \$ 5000 \text { are } \\
\text { needed to manufacture any } \\
\text { part of the module) }\end{array}$ & $\begin{array}{c}10 / 10 \\
(5.95 " \times 5.95 " \times 9.72 ")\end{array}$ & $\begin{array}{c}8.67 / 10 \\
(6.33 \\
\text { pounds) }\end{array}$ & $\begin{array}{l}10 / 10 \\
\text { (Module is able } \\
\text { to be lifted off of } \\
\text { the ground } \\
\text { without } \\
\text { separating, can } \\
\text { operate without } \\
\text { falling apart, } \\
\text { moving parts } \\
\text { operate properly } \\
\text { under load, and } 4 \\
\text { modules can } \\
\text { support a robot } \\
\text { weight of at least } \\
160 \text { pounds) }\end{array}$ & $\begin{array}{c}\text { 10/10 } \\
\text { (Encoder } \\
\text { directly } \\
\text { mounted to } \\
\text { rotating wheel } \\
\text { mount, no } \\
\text { belts or chains } \\
\text { used) }\end{array}$ & 5 \\
\hline $\begin{array}{l}\text { Best current } \\
\text { state-of-the- } \\
\text { art } \\
\text { (Westcoast, } \\
2021 \text { ) }\end{array}$ & $\begin{array}{c}9.3 / 10 \\
(\$ 685.37)\end{array}$ & $\begin{array}{c}5 / 10 \\
\text { (Number of parts is } 153 \text {, } \\
\text { machines over } \$ 5000 \text { are } \\
\text { needed to manufacture } \\
\text { multiple parts of the module) }\end{array}$ & $\begin{array}{c}10 / 10 \\
(5.5 " \times 5.5 " \times 9.6 ")\end{array}$ & $\begin{array}{c}9.5 / 10 \\
(5.5 \\
\text { pounds) }\end{array}$ & $\begin{array}{l}10 / 10 \\
\text { (Module is able } \\
\text { to be lifted off of } \\
\text { the ground } \\
\text { without } \\
\text { separating, can } \\
\text { operate without } \\
\text { falling apart, } \\
\text { moving parts } \\
\text { operate properly } \\
\text { under load, and } 4 \\
\text { modules can } \\
\text { support a robot } \\
\text { weight of at least } \\
160 \text { pounds) }\end{array}$ & $\begin{array}{l}\text { 0/10 } \\
\text { (Encoder is } \\
\text { not directly } \\
\text { mounted to } \\
\text { rotating wheel } \\
\text { mount, belts } \\
\text { used) }\end{array}$ & \\
\hline
\end{tabular}

\section{Design Iterations}

A brief description of the various design iterations is given below.

\section{Iteration 1 (Figure 3)}

The first functional Swerve Drive design is presented in Figure 3. This design utilizes a planetary gearbox, with an encoder mounted to it, to reduce rotational velocity and thus achieve better precision. Furthermore, it uses a chain to transfer torque from the gearbox to the pivoting wheel structure. A reduced rotational velocity is needed to drive the wheel in this configuration, as a result of using standard gears; the torque is transferred from the motor to a central shaft, which drives bevel gears. The gears power a chain, which then drives the wheel. $90^{\circ}$ brackets are used to connect the horizontal and vertical structural members of the pivoting structure. Lastly, a turntable is used to connect the bottom and top structures together, and to allow rotation between the two structures. 
Figure 3. Images from the First CAD Iteration of the Swerve Drive

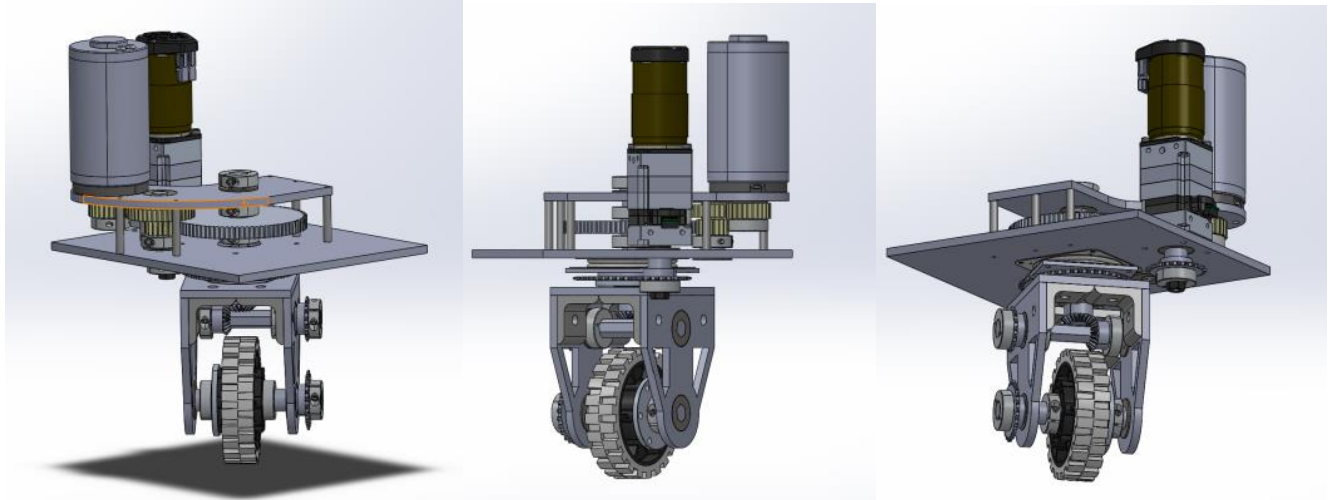

Iteration 2 (Figure 4)

Improving upon the first iteration, chains are replaced by a planetary gearbox directly above the bottom structure, which applies torque to a shaft mounted to the structure. The benefit of this gearbox placement is that the encoder is directly connected to the bottom structure, allowing a direct reading of the wheel direction. To drive the wheel, a motor powers a gear mounted onto the shaft, which pivots the bottom structure by placing a bearing in the center of the gear. Another gear is placed below the first one, and the torque is transferred between the two via a sixbolt circle. The bottom gear powers a shaft with a bevel gear on it, which transfers torque to a second bevel gear, directly powering the wheel. To accommodate for the new gear placement, a substantially larger turntable is used.

Figure 4. Images from the Second CAD Iteration of the Swerve Drive
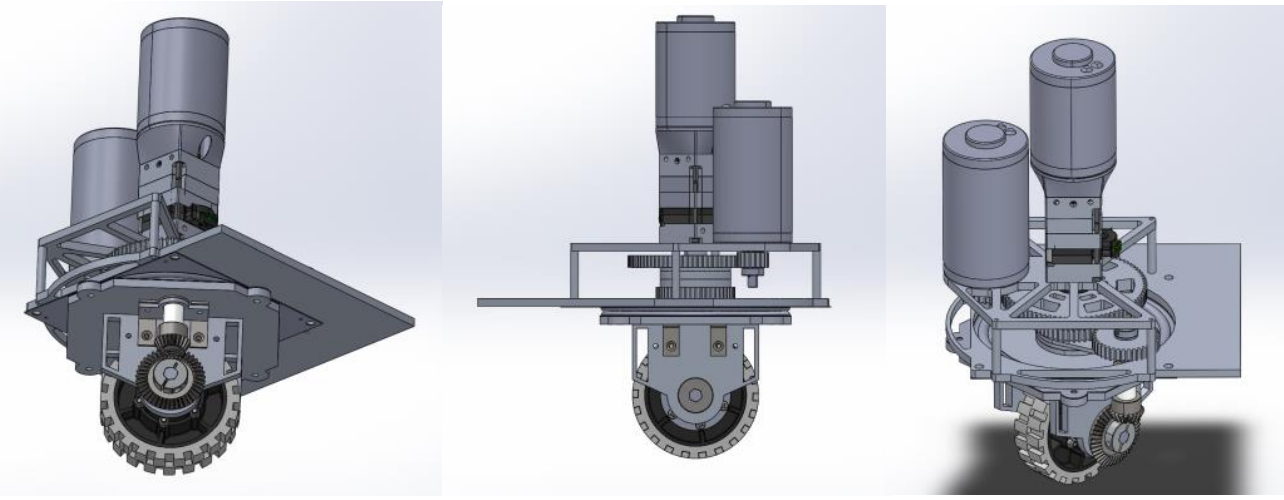

Iteration 3 (Figure 5)

Improving on the second iteration, the turntable is replaced by an "X-Contact" ball bearing (RBC Bearings 2021), which is held in place by a nut touching the outer ring on the top of the bearing, and a screw touching the same area on the bottom. $\mathrm{X}$-Contact bearings have two contact points on the outer ring raceway, and two contact points in the inner ring raceway, in an X-pattern. This allows the bearing to endure large vertical forces. Furthermore, the bearing is thin, allowing for the size 
of the module to be reduced substantially. In addition to the $90^{\circ}$ brackets connecting the vertical and horizontal members of the pivoting structure, there is a "prong" structure, shown in Figure 6, and described in the "Description of the Final Design" section of this paper.

Figure 5. Images from the Third CAD Iteration of the Swerve Drive
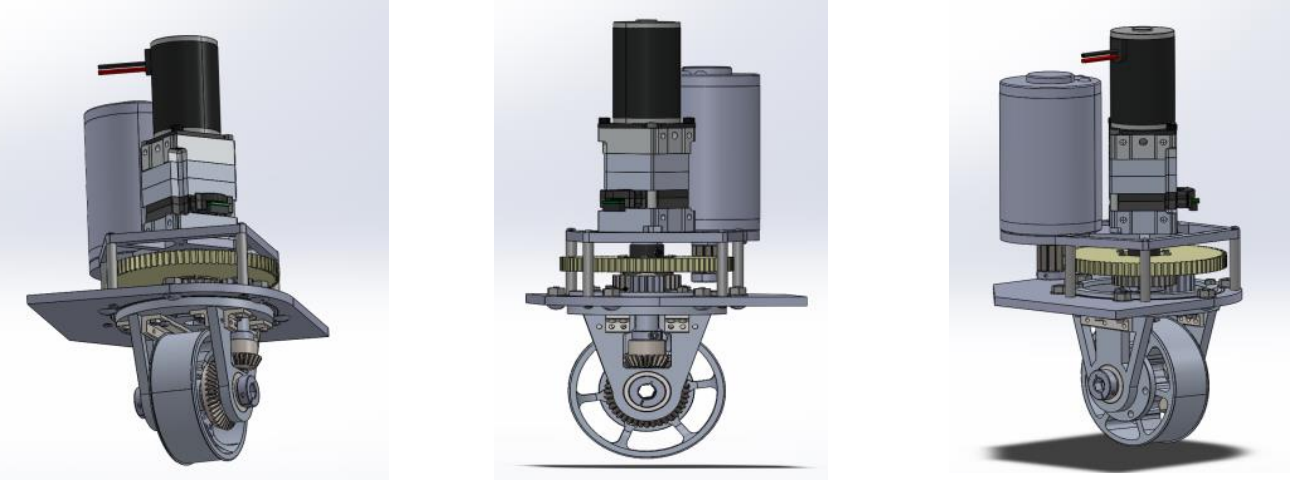

Iteration 4 (Figure 6)

Figure 6. Different Views of the Fourth CAD Iteration and Final Swerve Drive Design
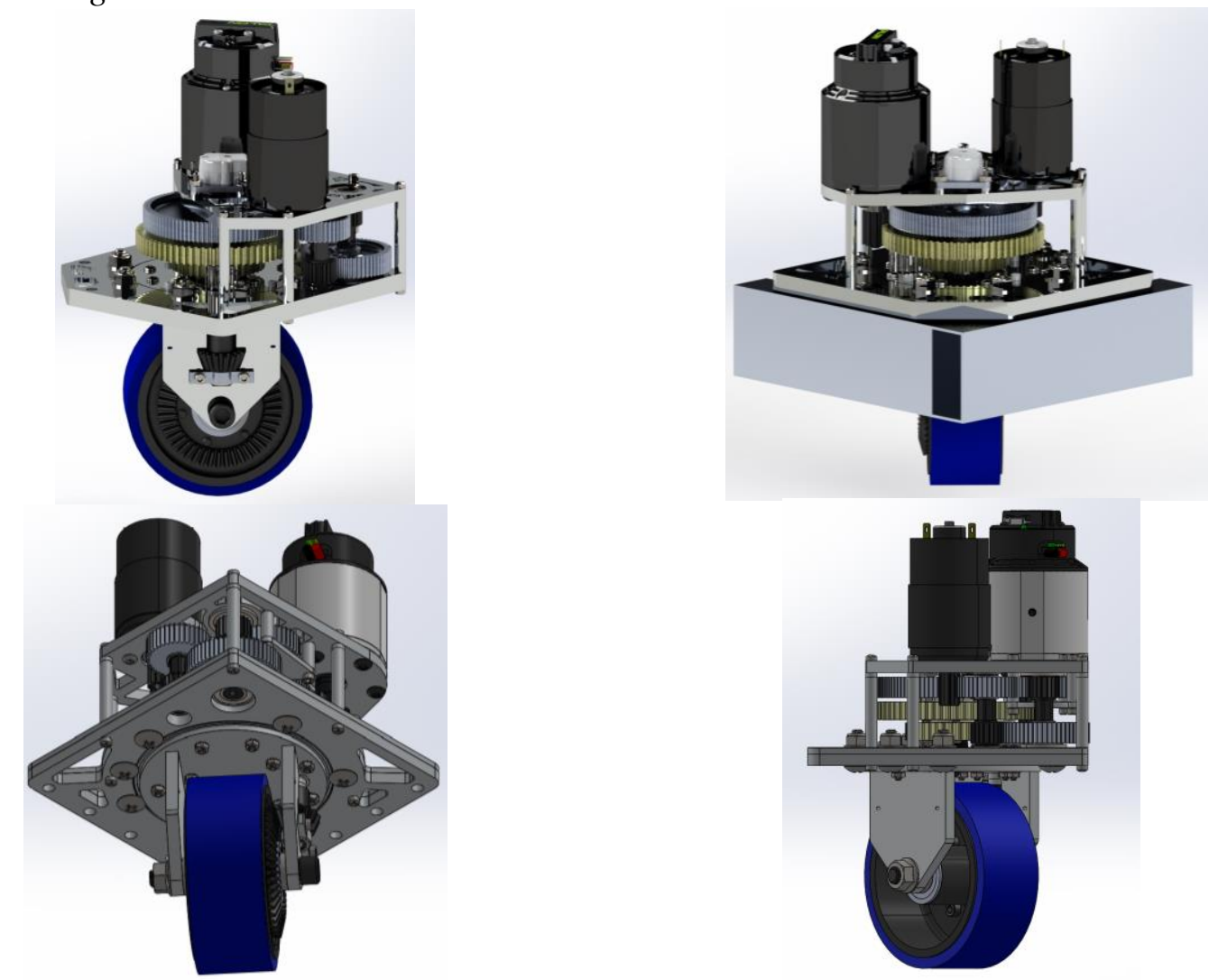
Improving on the third iteration, the planetary gearbox is replaced by normal gears. In this gear arrangement, the final pivoting gear is mounted onto a central shaft, just like the planetary gearbox in the third iteration. The vertical bevel gear is now supported below by a machined (using a CNC Mill) piece of 0.25 " aluminum, which has holes to mount it to a vertical wheel support bracket. To add extra support allowing for the removal of the $90^{\circ}$ brackets, holes are drilled into the top of the vertical wheel support brackets, which are then tapped using a hand tap allowing for a screw to secure the horizontal and vertical members of the structure together. To accommodate for the use of a spiral point tap, which pushes metal chips downwards, a small slot perpendicular to the hole is machined directly through the bracket, allowing for an exit for the chips from the hole.

\section{Results}

\section{Description of the Final Design}

Within the Swerve Drive there are two sub-mechanisms: a wheel pivoting mechanism, which changes the direction in which the wheel is pivoted, and a drive mechanism, which applies torque to the wheel. In this design, the drive mechanism is built around the wheel pivoting mechanism. The wheel pivoting mechanism is supplied torque by a 775 motor (Banggood 2021), which is small, lightweight, and relatively inexpensive. The motor has a maximum angular velocity of 21000 RPM, and there is a gear ratio of 50:1 between the pivoting structure and the motor, so the wheel can pivot at a maximum angular velocity of 420 RPM. This gear ratio was chosen to minimize the jitter caused by the DC motor, as well as any overshoot that may result from computational lag, while maximizing the angular velocity of the pivoting structure. To achieve this gear ratio, four-stages of gears were used and optimized to fit into the smallest possible volume. In Figure 7 each stage is represented by a box with the number of the stage next to it, and each gear is labelled with letters A-G, A being the first gear powered by the motor, and G being the last, which applies torque directly to the pivoting structure.

Stages 1 and 2 contain two gears on top of one another held in place by a retaining ring on a single hexagonal shaft. Gear $F$ is not needed to achieve the 50:1 gear ratio, but due to the placement of gear $\mathrm{E}$, it is needed to transfer torque between gears $\mathrm{E}$ and $\mathrm{G}$. The placement of gear D prohibits the use of a shaft running from gear $\mathrm{F}$ directly to a bearing on the bottom of the module, so a floating piece of machined 0.125 " aluminum, held in place by three standoffs, is utilized to securely hold a bearing below gear F, adding a second contact point for the shaft, securely holding the gear in place.

To transfer torque between gear $\mathrm{G}$ and the pivoting structure, a central shaft (black) is placed between the gear and the pivoting structure, as shown in Figure 8. 
Figure 7. Schematic of the Final Swerve Drive Design, Showing Four Stages of Gears and Each Individual Gear Used in the Wheel Pivoting Sub-Mechanism
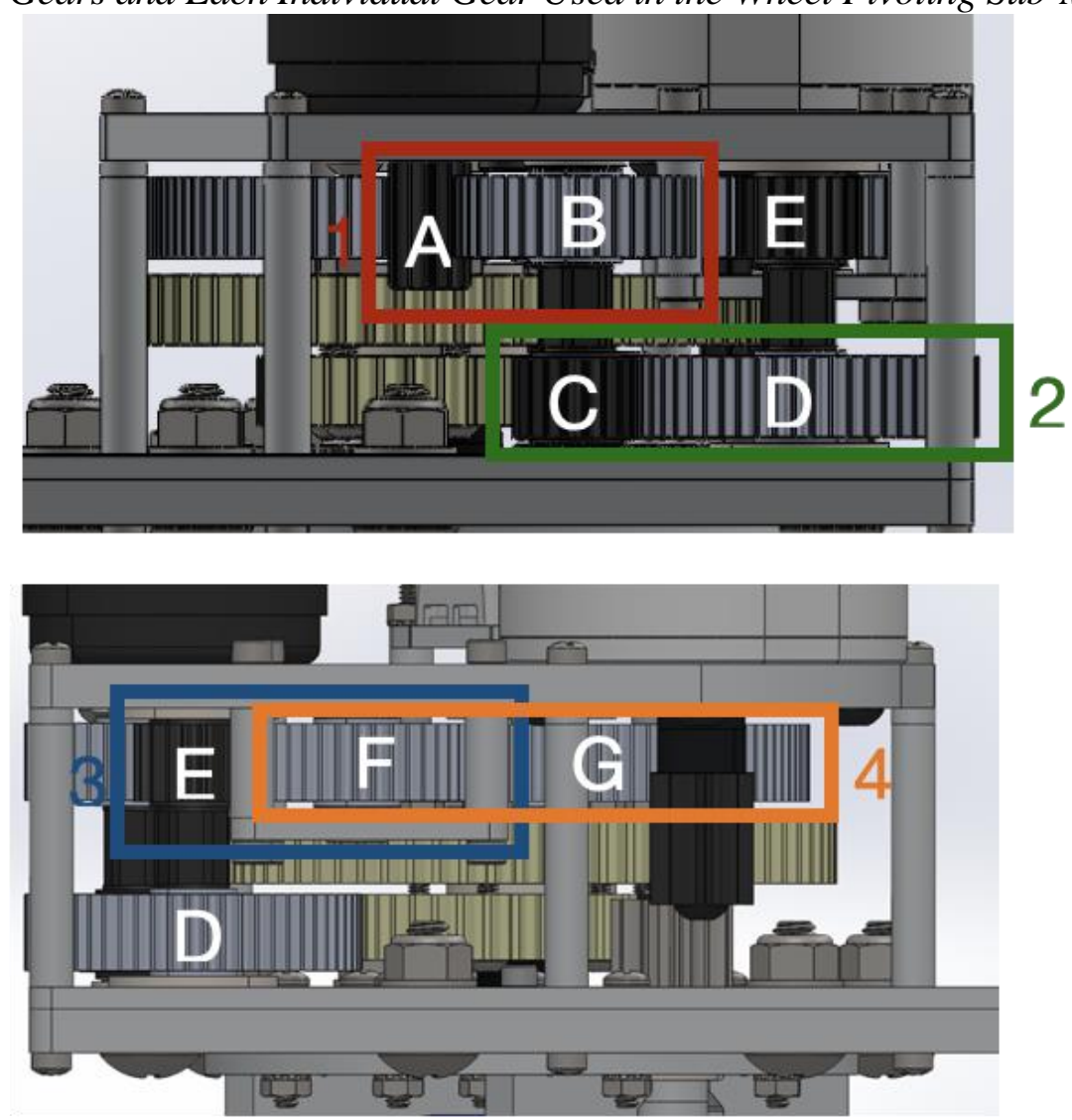

Figure 8. Cross Sectional CAD Image of the Final Swerve Drive Design

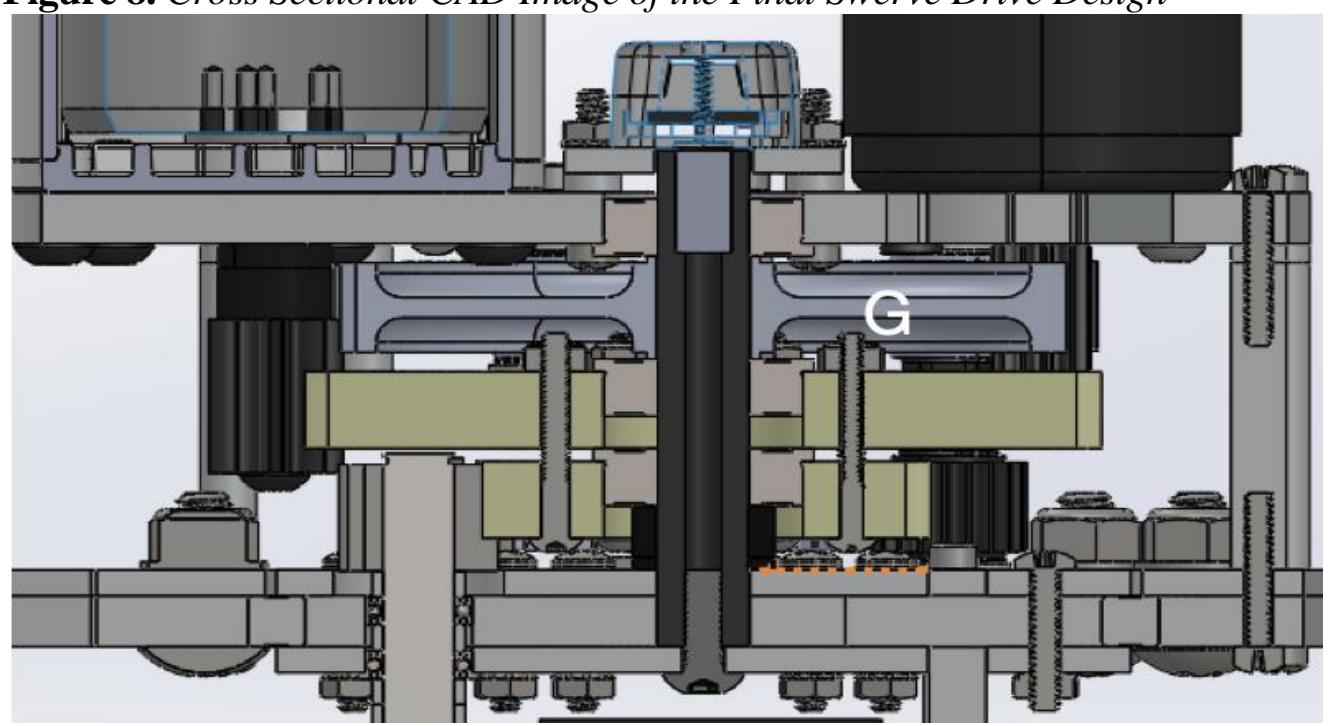

A polarized magnet is placed in this shaft, with an encoder directly above it to read the exact direction in which the wheel is pivoted. The encoder proposed for this design is (CTR CANcoder 2021). Please note that the encoder is only affected 
by metal very close to it. The encoder is not affected by metal that is further than 0.116 " away from it. Any steel frame that the module is mounted on would need to be substantially closer than 0.116 " away from the encoder to affect the precision of its readings. The shaft is threaded on the bottom, using a hand tap such as a spiral point tap, to allow for a screw to secure the shaft to the bottom pivoting structure. The polarized magnet is held securely in place within the shaft using epoxy glue.

Built around this wheel pivoting mechanism is the drive mechanism, supplied torque by a 400-watt brushless motor (CTR Electronics 2021a, b) with a maximum rotational velocity of $6380 \mathrm{RPM}$, a stall torque of $3.46 \mathrm{ft}-\mathrm{lbs}$, and a stall current of 257A. Depending on the application, different gear ratios for the drive mechanism may be used. In this application, a gear ratio of $6.44: 1$ is used, as it maximizes robot velocity at a theoretical maximum velocity of 17.26 feet/second, while allowing the robot to operate at full power for 3 minutes with an $18 \mathrm{Ah} 12 \mathrm{~V}$ lead acid battery (Home Depot 2021a). To achieve this gear ratio, three-stages of gears are used. In Figure 9 each stage is represented by a box with the number of the stage next to it and each gear is labelled with letters A-F, A being the first gear powered by the motor and $\mathrm{F}$ being the last, which applies torque directly to the wheel.

Figure 9. Schematic of the Final Swerve Drive Design Showing the Three Stages of Gears and Each Individual Gear In the Wheel Driving Sub-Mechanism

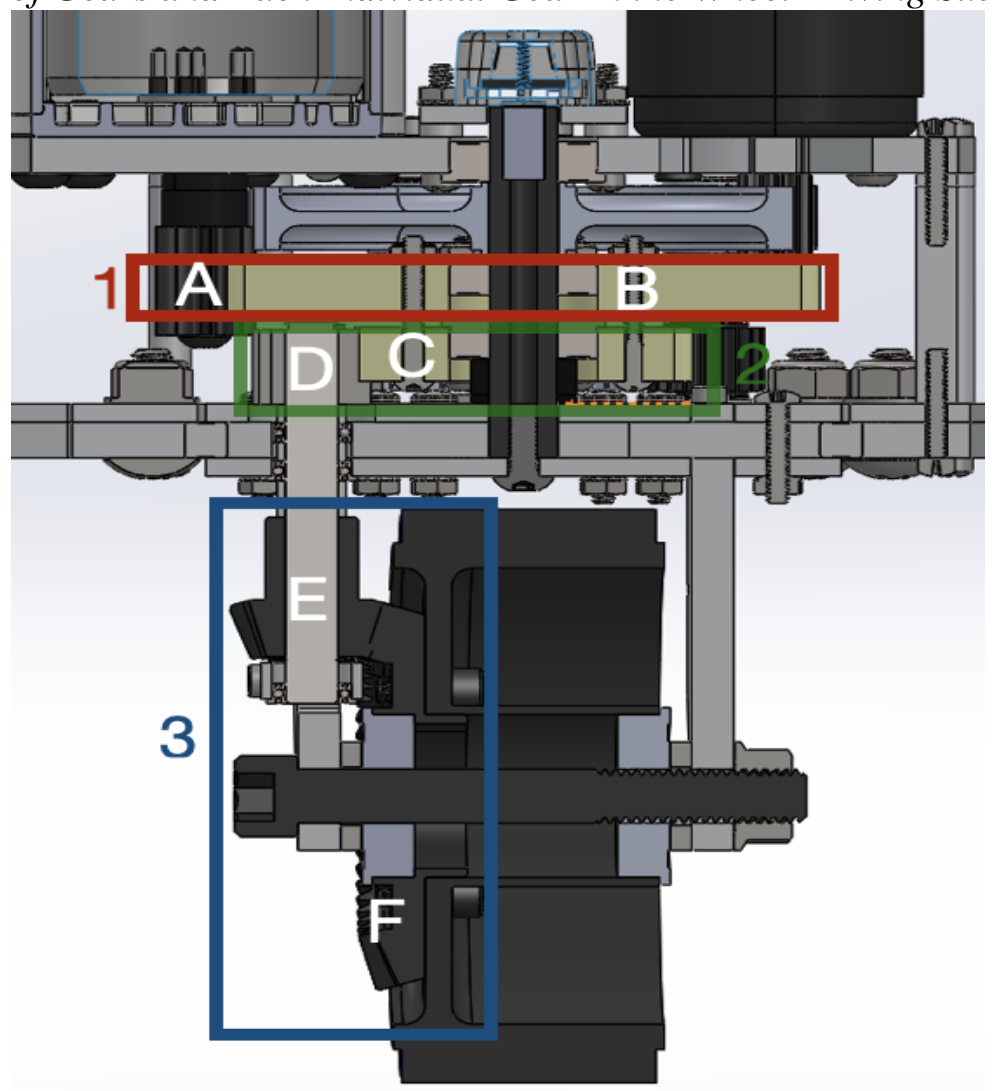

Stage 1 contains a pinion gear (A), mounted on the motor, which drives a spur gear (B). Stage 2 contains a large gear (C), driving a small gear (D). To connect 
gears $\mathrm{B}$ and $\mathrm{C}$, a 6-bolt circle is drilled into them using a vertical drill press (Home Depot 2021b). To ensure that all six holes are drilled into the gears precisely, a wooden "stencil" is machined using a CNC Mill (Stepcraft 2021). The stencil is held in the direct center of the gear using a small protrusion in the gear, which exists before the bearing bore is drilled. Using tape or glue, the stencil is then held in place rotationally, allowing for the holes to be drilled into the gear using the vertical drill press, with the wooden stencil as a reference. A bearing bore is then drilled into the center of the gears, so that bearings can allow for the hexagonal shaft, which pivots the bottom pivoting structure, to run through the gears. Gears B and $\mathrm{C}$ originally have a hexagonal bore, so that the drill bit for the bearing bore is placed so that it is tangent to all six sides of the hex bore. After the bearing bore and the six-bolt circle are drilled into the gears, a flanged bearing is placed so that its flange is above gears $\mathrm{B}$ and $\mathrm{C}$ individually. This allows gear $\mathrm{G}$ of the pivoting mechanism to be held securely in place above gear $\mathrm{B}$ of the drive mechanism. The flange of the bearing in gear $\mathrm{C}$ allows for a small gap between gears $\mathrm{B}$ and $\mathrm{C}$, while holding gear B in place above gear C. Plastic spacers below the bearing of gear C keep both gears C and B in the correct position on the hexagonal shaft. Six nuts and bolts placed through the six-bolt circle of the gear, with space for the nuts above gear $\mathrm{B}$ resulting from a pocket, made by the manufacturer in gear $\mathrm{G}$ of the pivoting mechanism, hold securely gears $\mathrm{B}$ and $\mathrm{C}$ together. Next, gear $\mathrm{D}$ is held securely in place on a key shaft with a retaining ring above and custom 0.125 " aluminum spacers below. There is space for the retaining ring above gear $\mathrm{D}$ because the flange in the bearing of gear $\mathrm{C}$ makes a gap between gears $\mathrm{B}$ and $\mathrm{C}$. A key in gear D allows the gear to apply torque to the key shaft which drives gear E. To achieve the proper gear ratio, and to transfer rotation around the vertical axis of the key shaft to the horizontal axis, which the wheel rotates around, two bevel gears are used in stage 3. Torque can be applied on gear $\mathrm{E}$ by a key running through a key shaft. Gear E then applies torque to gear F, which is held securely in place on the wheel using a six-bolt circle on both the wheel and the gear. The six-bolt circle on gear F is tapped by the manufacturer, allowing for six bolts to hold the gear and the wheel securely in place. This allows the module to drive a 4" diameter wheel.

To structurally support the pivoting and drive sub mechanisms a framework utilizing standoffs, nuts and bolts, and 0.125 " and 0.25 " aluminum components was machined using a sub-\$5000 CNC Mill (Stepcraft 2021) and was tapped/threaded using various types of manual taps, including spiral point taps. Figure 10, shows the key innovative aspects of the Swerve Drive structure, which allow the module to be manufactured with a sub-\$5000 CNC Mill (Stepcraft 2021).

Image 1 in Figure 10 shows the entire structure, which includes the upper and lower portions of the module, while image 2 shows the upper structure. Circled in red are the module mount plates which consist of 0.25 " and 0.125 " thick aluminum plates bolted to one another using 0.25 " diameter bolts and nylon insert locknuts. The central circle of the 0.125 " module mount plate is slightly smaller in diameter than that of the 0.25 " module mount plate, so that the 0.125 " plate has a contact point with the top of the outer ring of the central X-Contact bearing (RBC Bearings 2021). This bearing connects the upper and lower structures, while allowing 
rotational movement between the two to ensure that a vertical force applied to the wheel and the lower structure is safely transferred to the robot.

Using standoffs and bolts, the motor mount plate, circled in black in image 2, is securely attached to the module mount plates. The motor mount plate has holes to allow for the motors of the drive and pivoting sub-mechanisms to mount securely to the plate. Holes in both the module mount plate and the motor mount plate, machined using a CNC Mill (Stepcraft 2021), accommodate the bearings which support the shafts of the pivoting and drive mechanisms. Circled in green in image 2 is the encoder mount, which is a floating piece of 0.125 " thick of aluminum, held in place with four standoffs, four screws, and four locknuts. The encoder is placed on this component to allow placement of the bearing that supports the central shaft, which pivots the lower pivoting structure. Because the encoder is a magnet encoder, all components close to it, including the mount, are made of aluminum.

In image 3 the X-Contact bearing and seven bolts with their heads touching the outer ring of the bearing are circled in orange. These bolts ensure that if the module is lifted off of the ground, the upper and lower structures do not detach from each other. Furthermore, if uneven forces are applied on the circumference of the bearing, both sides of the bearing will stay in place. Image 4 shows the floating structure, which holds the shaft of gear $\mathrm{F}$ of the pivoting mechanism in place, circled in blue. This structure, machined using a CNC Mill, consists of 0.125 " aluminum with a hole for a bearing in the center and holes for three screws which connect to three standoffs to the motor mounting plate.

Image 5 shows the lower structure. The red and blue arrows point to two 0.125 " aluminum plates placed above and below the X-Contact bearing. Going through these plates are prongs protruding from the top of the wheel supports, shown by black and orange arrows in the figure. In these prongs are rectangular holes, which are circled in red in image 7. "Sandwiched" between the two 0.125 " aluminum plates placed above and below the $\mathrm{X}$-Contact bearing are 3 components, labelled A-C in image 6. Going through components $\mathrm{A}$ and $\mathrm{C}$ are the wheel supports, labeled $D$ and $E$ in image 6 . Going through the rectangular hole in the prong of component $\mathrm{D}$ is component $\mathrm{A}$, which has a prong of its own and screws, which run through the two 0.125 " aluminum plates and itself. Component $\mathrm{A}$ is circular on the outside, with a radius matching the inner ring of the $\mathrm{X}$-Contact bearing and placed inside the inner diameter of the bearing. To allow the key shaft and bevel gear to run through it, component $\mathrm{E}$ has two prongs with rectangular holes in them. Running through these rectangular holes are the two prongs of component $\mathrm{C}$, which is supported by screws running through the aluminum plates above and below the bearing.

Component $\mathrm{C}$, like $\mathrm{A}$ is also designed to be placed inside the inner diameter of the bearing. Component $\mathrm{B}$ is placed between components $\mathrm{A}$ and $\mathrm{C}$ with a bore in the center for the hexagonal shaft that rotates the bottom pivoting structure. In image 7, a hole running through components $\mathrm{E}$ and component $\mathrm{D}$ is circled in orange. This hole, threaded to allow for a screw to run from the 0.125 " aluminum plate above the X-Contact bearing through components $\mathrm{D}$ and $\mathrm{E}$, adds extra support to the wheel. To allow for this hole to be threaded by a tap that is not 
meant for blind holes, such as a spiral point tap, a small oval-shaped hole, circled in black in image 7, was machined horizontally through components D and E using a CNC Mill. This hole allows for the metal chips "produced" by the tap to escape through the bottom of the hole, ensuring that the hole is properly threaded and the tap does not fail.

In image 8, two flanged ball bearings are circled in blue and green. The flanged bearing circled in green is supported below by component $\mathrm{E}$ using small flanges circled in red, touching the outer ring and flange of the bearing. The flanged bearing circled in blue in image 9 is supported below by a flange (also circled in blue), which touches the outer ring and flange of the bearing. The bearing is supported above by a 0.25 " piece of aluminum machined using a CNC Mill. This component has a ring shape in the center to support the bearing and two portions on either side, which stick out and have a horizontal hole drilled into them using a drill press. These holes accommodate screws, which go into holes machined into component $\mathrm{E}$, circled in red in image 9. The holes in component $\mathrm{E}$ are also tapped to allow for the bearing support to be held securely in place.

Figure 10. The final Swerve Drive Design

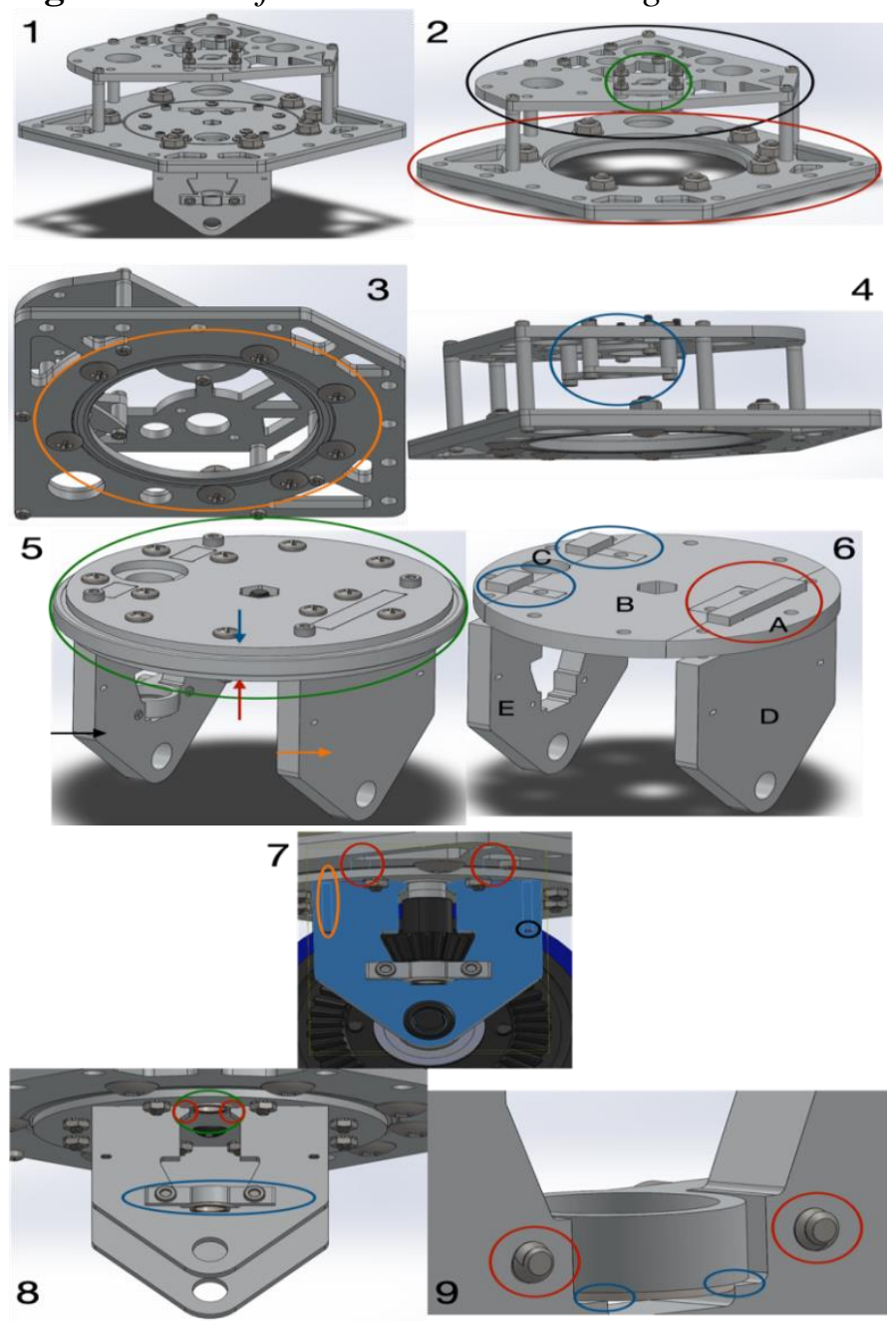




\section{Building and Testing a Physical Prototype}

Since the CAD of the Swerve Drive module is now complete, a prototype module can be manufactured. The silver components shown in Figure 8 are made of 1/8" and 1/4" aluminum which can be machined using a CNC Mill. All other components (i.e., gears, spacers, etc.) can be purchased directly from distributors like McMaster Carr (McMaster-Carr 2021). Unfortunately due to the Covid-19 Pandemic the metal components required to make the Swerve Drive module could not be bought or manufactured.

Figure 11. Several Images of the Prototype Swerve Drive Module, Along with the Images of the Dolly Swerve Drive Prototype Assembly

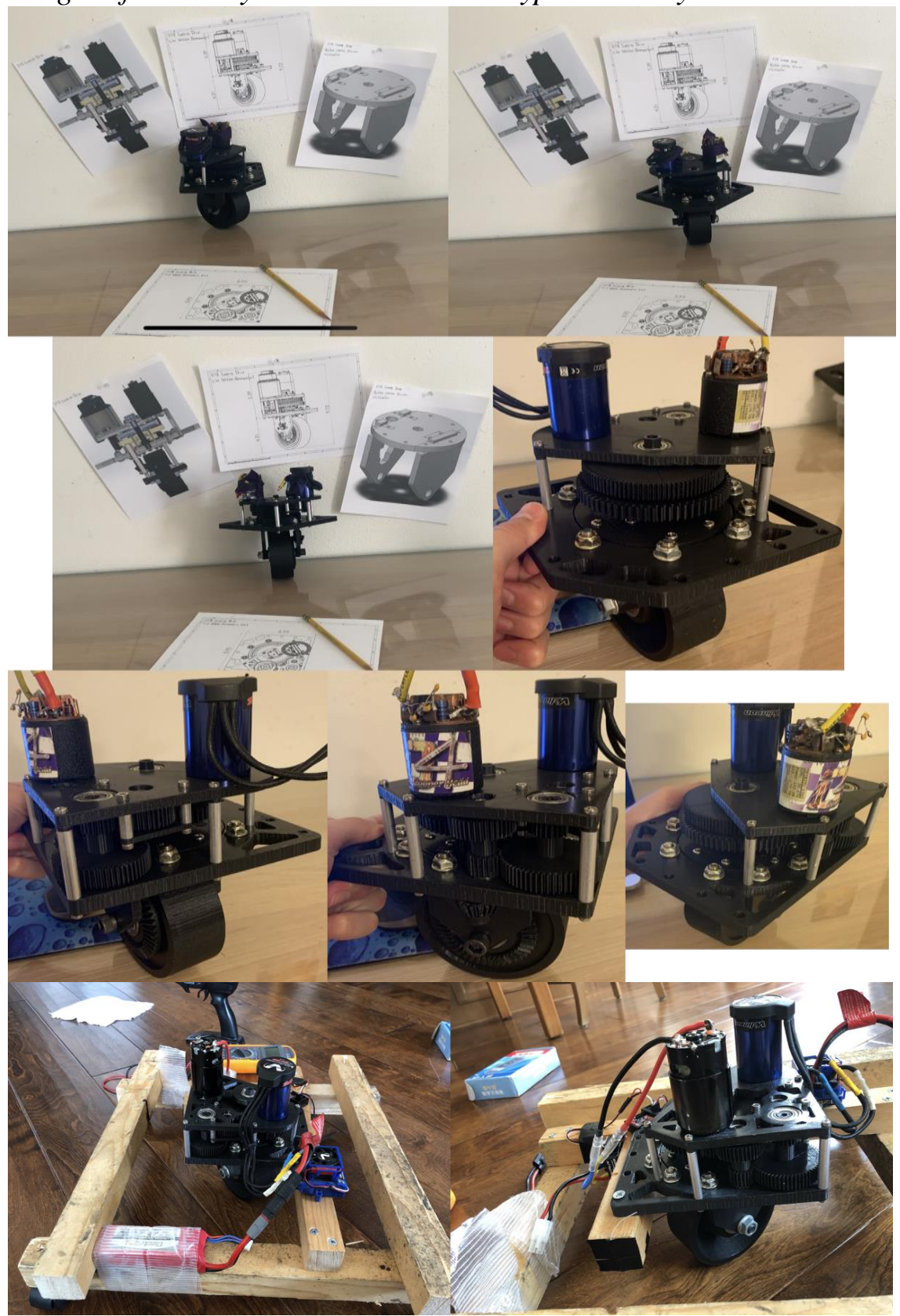


All components were manufactured with an Ender 3 Pro 3D printer (Creality 2021), with the exception of screws, standoffs, and spacers, which were purchased online (McMaster-Carr 2021). Thus a working prototype was built. To demonstrate functionality the motors for the module were connected to electronic speed controllers (ESCs), which were then attached to the receiver and transmitter of a remote-control car. For a fully functioning robot, the motors would have been controlled by an onboard computer. However, this was beyond the scope of this prototype, which was to manufacture a single Swerve Drive module prototype. Hence a dolly was constructed out of wood and four caster wheels and the Swerve Drive module was placed in the center of it. Using the remote control, it was possible to demonstrate the functionality of the Swerve Drive module prototype. The acceleration and turn speed of the module were exceptional. The structure was able to pivot 360 degrees around the vertical axis in less than one-second, while the wheel spun at more than 3,200 rotations per minute. In Figure 11, several images of the prototype Swerve Drive module, along with the images of the dolly Swerve Drive prototype assembly are shown.

\section{Discussion}

In the final Swerve Drive design, a DC motor with a 50:1 gear ratio, along with an encoder, is used to pivot the structure about the vertical axis. This setup offers exceptional accuracy and rotational velocity, and although is lighter, cheaper, and smaller than the best current state-of-the-art option (Westcoast Products 2021), it can still be improved. For example, in a future project, the pivoting motor could be replaced by a stepper motor (Pololu Robotics \& Electronics 2021). This would eliminate the need for some gears, the DC motor, and the encoder, making the module lighter, smaller, and cheaper.

\section{Conclusions}

This paper presented the design of an advanced Swerve Drive module. Swerve Drive is a modular assembly, which consists of a driven wheel and a base that rotates symmetrically around the vertical axis running through the center of the wheel. There are two motors, one which drives the wheel, and the other which rotates the base around the vertical axis. This allows a robot which utilizes Swerve Drive to spin while moving along any designated path. A robot which utilizes Swerve Drive would typically contain four Swerve Drive modules. Each wheel can rotate while at the same time pivoting along the vertical axis. This configuration allows a high level of robot maneuverability.

A prototype was also manufactured using a 3D printer. The prototype verified the mechanical functionality of the proposed design, according to the design criteria and constraints set in the paper. The designed Swerve Drive module has similar properties to the best current design in four out of six metrics, while it does 
significantly better in the other two out of six metrics, thus establishing this design as the new state-of-the-art.

In our current society, mobile robots are used to combat COVID-19 in hospitals, the transportation of goods in and across warehouses and distribution centers, in space programs, as well as in specific functions in stores, to name a few applications. The Swerve Drive design described here will help with the advancement of autonomous mobile robots. This advancement will allow autonomous mobile robots to be used in many more tasks in today's world.

\section{References}

Ackerman E (2020, March 11) Autonomous robots are helping kill Coronavirus in hospitals. Available at: https://bit.ly/3Ji048c.

Banggood (2021) 775 motor. Available at: https://bit.ly/3BiqHqV.

Bloss R (2011) Mobile hospital robots cure numerous logistic needs. Industrial Robot 38(6): 567-571.

Cardona M, Cortez F, Palacios A, Cerros K (2020) Mobile robots application against Covid-19 pandemic. In 2020 IEEE ANDESCON, 1-5.

Carothers J (2014) Design of a triple singularity drive for mobile wheeled robots. BSME Thesis. Department of Mechanical Engineering, Massachusetts Institute of Technology.

Ciment S (2020, January 13) Walmart is bringing robots to 650 more stores as the retailer ramps up automation in stores nationwide. Insider.

Creality (2021) Ender 3 pro 3D printer. Available at: https://www.creality3dofficial.com/ products/creality-ender-3-pro-3d-printer.

CTR Electronics (2021a) Falcon 500 motor. Available at: http://www.ctr-electronics.com/ talon-fx.html.

CTR Electronics (2021b) CANcoder. Available at: https://store.ctr-electronics.com/canco der/.

Dassault Systems. (2021) Solidworks. Available at: https://www.solidworks.com/.

Dunakin C (2020, August 28) 5 ways autonomous mobile robots are transforming warehouses. Available at: https://6river.com/how-autonomous-mobile-robots-are-tran sforming-warehouses/.

Home Depot (2021a) 18 Ah 12 volt lead acid battery. Available at: https://www.homede pot.com/p/MIGHTY-MAX-BATTERY-12-Volt-18-Ah-Sealed-Lead-Acid-SLA-Rec hargeable-Battery-ML18-12/308036944.

Home Depot (2021b) Floor standing drill press. Available at: https://www.homedepot. com/p/Jet-1-HP-15-in-Floor-Standing-Drill-Press-6-Speed-115-230-Volt-J-A3816-3 $54500 / 204357268$.

Lieherr (2021) Gear hobbing machine. Available at: https://bit.ly/3rLTfG0.

Melanson T (2018) Mobile robots and COVID-19-Helping healthcare workers. Blog AP, Blog EU, News, News AP, News EU.

Mars 2020 mission perseverance rover: wheels and legs. Available at: https://mars.nasa. gov/mars2020/spacecraft/rover/wheels/.

McMaster-Carr (2021) Available at: https://www.mcmaster.com/.

NASA Technology Transfer Program (n/a) Modular Robotic Vehicle (MRV). Available at: https://technology.nasa.gov/patent/MSC-TOPS-74.

Pololu Robotics \& Electronics (2021) Stepper motors. Available at: https://www.pololu. com/category/87/stepper-motors.

RBC Bearings (2021) X-contact bearing description. Available at: https://bit.ly/3HM9VmB. 
Seidita V, Lanza F, Pipitone A, Chella A (2021) Robots as intelligent assistants to face COVID-19 Pandemic. Briefings in Bioinformatics 22(2): 823-831.

Simon M (2019, June 5) Inside the Amazon warehouse where humans and machines become one. Wired, Science.

Stepcraft (2021) D.840 Mill \& Carve CNC package. Available at: https://www.stepcraft. us/shop/product/70012-d-840-mill-carve-cnc-package-755?search=840.

Swerve Central (2021) Available at: https://team1640.com/wiki/index.php/Swerve_Central.

Swerve Drive Specialties (2021) Specialties module. Available at: https://www.swervedri vespecialties.com/products/mk3-swerve-module.

Tormach (2021) PCNC 440CNC mill. Available at: https://tormach.com/pcnc-440-starterpackage.html.

Westcoast Products SS Swerve (2021) Available at: https://www.wcproducts.com/. 